Int. J. Electrochem. Sci., 14 (2019) $6920-6937$

\title{
Synergistic Effect on the Electrochemical Performances of Polypyrrole Nanoparticles Distributed on the Graphene Layers as an Electrodes for Supercapacitors
}

\author{
Sarah Umeera Muhamad ${ }^{1}$, Nurul Hayati Idris ${ }^{1, *}$ and M. F. Md Din ${ }^{2}$ \\ ${ }^{1}$ Energy Storage Research Group, School of Ocean Engineering, Universiti Malaysia Terengganu, \\ 21030 Kuala Nerus, Terengganu, Malaysia \\ ${ }^{2}$ Department of Electrical \& Electronic Engineering, Faculty of Engineering, National Defence \\ University of Malaysia, Kem Sungai Besi, 57000 Kuala Lumpur, Malaysia. \\ *E-mail: nurulhayati@umt.edu.my
}

doi: $10.20964 / 2019.07 .74$

Received: 15 October 2018 / Accepted: 9 May 2019 / Published: 10 June 2019

\begin{abstract}
The polypyrrole (PPy) nanoparticles distributed on the graphene layers are prepared via in-situ polymerization method. The amount of PPy on the graphene layers is varied in order to obtain the highest electrochemical performances. The PPy in graphene/PPy refers to nanoparticles with a diameter size of $0.19 \mu \mathrm{m}$. The graphene/PPy exhibited excellent electrochemical performances when $80 \mathrm{wt} \%$ of PPy was added into the composite, with specific capacitance of approximately $270 \mathrm{~F} \mathrm{~g}^{-1}$ at a current density of $500 \mathrm{~mA} \mathrm{~g}^{-1}$. Furthermore, $77 \%$ of initial capacitance was retained after 1000 charge/discharge cycles, which suggests good cycling stability of the composite at a current density of $5000 \mathrm{~mA} \mathrm{~g}^{-1}$. The improved electrochemical performances of the composite are attributable to the synergistic effect of the PPy nanoparticles and crumpled graphene layers, which gave large surface area, short ion diffusion pathway, excellent rate performance, and cycling stability.
\end{abstract}

Keywords: supercapacitor; graphene; polypyrrole; synergistic effect; capacitance

\section{$\underline{\text { FULL TEXT }}$}

(C) 2019 The Authors. Published by ESG (www.electrochemsci.org). This article is an open access article distributed under the terms and conditions of the Creative Commons Attribution license (http://creativecommons.org/licenses/by/4.0/). 